\title{
Efficacy of Single and Combined Leaf Powder of Nicotiana Tabacum L. [Solanales: Solanaceae] with Reduced Rates of Pirimiphos-Methyl in Management of Sitophilus Zeamais Motschulsky [Coleoptera: Curculionidae]
}

\author{
J. E Idoko \& R. A. Adebayo (Corresponding author) \\ Department of Crop, Soil and Pest Management \\ School of Agriculture and Agricultural Technology \\ Federal University of Technology Akure, Ondo State, Nigeria \\ Tel: 234-703-866-1128 E-mail: abiodun1400@yahoo.com
}

\begin{abstract}
The toxicity effects of the combination of Nicotiana tabacum leaf powder and pirimiphos-methyl dust as a treatment is compared with sole treatment of the powder and dust in this study. All laboratory experiments were conducted under prevailing conditions of $28 \pm 3^{\circ} \mathrm{C}$ and $70 \pm 5 \%$ relative humidity. Contact toxicity of Nicotiana tabacum powder was tested on Sitophilus zeamais at $0.4 \mathrm{~g}$ and $0.01 \mathrm{~g}$ of pirimiphos-methyl powder per $20 \mathrm{~g}$ of maize seeds singly. The toxicity of combined powder of $N$. tabacum at $0.2 \mathrm{~g}$ with $0.0013 \mathrm{~g}, 0.0025 \mathrm{~g}$ and $0.005 \mathrm{~g}$ of pirimiphos-methyl dust per $20 \mathrm{~g}$ of maize seeds was also tested. These treatments significantly $(\mathrm{p}>0.05)$ reduced the weight loss and adult emergence of $S$. zeamais. The powder and dust also caused high mortality to $S$. zeamais when applied.

The efficacy of the Nicotiana tabacum was better when applied singly at $0.4 \mathrm{~g}$ than when combined with dust of pirimiphos-methyl at reduced rates. Irrespective of the treatment used in the study, the response of Sitophilus zeamais was found to be dependent on the concentration. Adult mortality increases with concentration, while adult emergence reduces. The results of this study revealed the effects of combined botanicals with reduced rates of conventional insecticides as an alternative in the management of stored product insect pests.
\end{abstract}

Keywords: Nicotiana tabacum, Sitophilus zeamais, Pirimiphos-methyl, Mortality, Adult emergency

\section{Introduction}

Maize (Zea mays L.) is one of the most popular crop plants all over the world, grown in over 140 million hectares (Zaidi and Singh, 2005). It is the most important cereal in sub-Sahara Africa and provides many families with the much-needed nutrient (Kling and Edmeades, 1997). Annual maize demand in sub-Saharan Africa is expected to double to 52 million tonnes by 2020 (CIMMYT, 2004). Maize is a stable cereal crop in many parts of Africa and it has replaced many traditional starchy foodstuffs, such as sorghum and millet, particularly in South Africa, Malawi, Zimbabwe and Kenya, and in considerable sections of Angola, Zambia, Tanzania, Mozambique, Cameroon, Benin, Togo, Ghana, Nigeria and Egypt (Purseglove, 1992). It is comparable in significance to rice in Asia and wheat in the Middle East (Kim, 1987). It is an important source of carbohydrate and forms about $90-95 \%$ of the total calories intake of the coastal Savanna people (Baba, 1994; Dankyi et al., 1995). However, during storage, maize seeds are very susceptible to attack by several insect pest prominent among of which is Sitophilus species. Attack by insect and other pests in storage often result in significant losses including loss of viability (ISTA, 1995). Post harvest storage of maize is greatly constrained by the pest, Sitophilus zeamais Motschulsky. Damage to maize grain begins from the field just before harvest and the insects are carried into the store where the population builds up rapidly (Appert 1987; Adedire and Lajide 2003).

The control of storage insects like $S$. zeamais has centred mainly on the use of synthetic insecticides ( Asawalam et al.,2007). The most popular practice in protecting stored seeds against pest damage is the use of synthetic crop protection agents ( Crepsy and Legarde, 1973).

There are however major setback to the use of synthetic pesticides including the risk to the user as well as high cost of procurement, development of resistant strains and residue in the food crops which has led scientists to investigating plant products as alternatives (Lale, 2002). Amongst the plant products which have been reported 
to be effective in store are Azadirachta indica (Adedire and Ajayi, 1996, Piper guineense ( Ofuya and Dawodu, 2002; Asawalam et al.,2007). This study was carried out to determine the potential of mixing Nicotiana tabacum leaf powder with reduced rate of pirimiphos-methyl dust in management of Sitophilus zeamaiz Mots.

\section{Materials and Methods}

This study was conducted in the entomology laboratory of the Department of Crop, Soil and Pest Management, Federal University of Technology Akure, Ondo State, Nigeria in 2009.

\subsection{Culturing of Sitophilus zeamais}

The original Sitophilus zeamais used was derived from a colony originating from infested maize seeds collected from oja oba market in Akure, Ondo State, Nigeria. The emerged adults were sub-cultured in the laboratory and the sub-culture was maintained in Kilner jars containing 500g weevil susceptible maize in the laboratory at $28 \pm 3^{\circ} \mathrm{C}$ and $70 \pm 5^{\circ} \%$ relative humidity.

The clean yellow maize grains used for the experiment were obtained from the Agricultural Development Program (ADP) office, Akure. Prior to experiments, the grains were sterilized for 3 hours in a Gallenkamp oven at a temperature of $60^{\circ} \mathrm{C}$ to kill any available insects and other microorganisms in them (Allotey and Azalekor, 2000).

\subsection{Preparation of plant material}

Fresh leaves of Nicotiana tabacum were gotten from the crop-type museum, Department of Crop, Soil and Pest Management, Federal university of technology, Akure and air dried in the Laboratory, unwanted materials were removed to make it clean. Thereafter, it was finely grinded with a mortar and pestle and kept in separate plastic containers with tightly fitted lids and placed in a wooden cupboard in the laboratory for future use.

\subsection{Bioassay of the powder Nicotiana tabacum and dust of pirimiphos-methyl}

Twenty grams $(20 \mathrm{~g})$ of clean and weevil susceptible maize grains were weighed into petri-dishes each of which $0.4 \mathrm{~g}$ and Nicotina tabacum powder was added separately. Ten pairs of unsex adult S. zeamais were introduced into each of the petri-dishes. The contents of the plastic were then shaken vigorously for proper admixture. The experiment was arranged in completely randomized design. The number of dead insects in each dish was counted and recorded for a period of 7 days to estimate maize weevil mortality. Treatment and control were replicated three times.

Pirimiphos-methyl dust was tested at a reduced rate of $0.01 \mathrm{~g}$ per $20 \mathrm{~g}$ of maize grains using the procedure described for Nicotiana tabacum powder. A week after infestation, all insects were removed. Number of adults that emerged was counted 31 days post infestation and recorded for 7 days consecutively.

Combined treatment of pirimiphos-methyl dust and Nicotiana tabacum powder at different concentrations of $0.005 \mathrm{~g}+0.2 \mathrm{~g}, 0.0025 \mathrm{~g}+0.2 \mathrm{~g}, 0.0013 \mathrm{~g}+0.2 \mathrm{~g}$ were all tested on Sitophilus zeamais following the same procedure described above. Data on adult emergence, mortality and weight loss after emergence were recorded.

\subsection{Statistical Analysis}

Data obtained were subjected to analysis of variance (ANOVA) and Genstat software version 5 Release 3.2 (Lawes Agricultural Trust, 1995).Significant differences at $(\mathrm{P}>0.05)$ were separated using Least Significant Difference (LSD). Data on adult mortality were subjected to log transformation while those on adult emergence and weight loss were transformed using square root transformation to normalize the data for analysis.

\section{Results and discussion}

\subsection{Mortality}

Figure 1 shows the mortality of maize weevil as a result of the treatments. All treatments caused at least mortality of 15 adults except the control with only 2 dead adults. Treatment $1(0.4 \mathrm{~g} \mathrm{~N}$. Tabacum $)$ was however, the best as it caused highest mortality to the weevil when compared to other treatments combination.

\subsection{Adult emergence}

Both powder and dust used in all combinations reduced adult emergence of maize weevil when compared with the control (Fig. 2). Adult emergence was least in maize grain treated with $0.4 \mathrm{~g}$ of $N$. tabacum (treatment 1) while control (treatment 6) had the highest number of adult emergence. The number of adult emergence was similar in treatments that received $0.1 \mathrm{~g}$ of PM (treatment 2) and $0.2 \mathrm{~g} \mathrm{NT}+0.005 \mathrm{~g}$ PM (treatment 3 ) and between $0.2 \mathrm{~g} \mathrm{NT}+0.0025 \mathrm{~g}$ PM (treatment 4) and $0.2 \mathrm{~g} \mathrm{NT}+0.0013 \mathrm{~g}$ PM (treatment 5). 


\subsection{Weight loss}

The weight loss of treated maize grains was lower compared to the grains that received no treatment (control) Fig. 3. The result of weight loss after emergence of the weevils followed the same pattern as the emergence of weevils. Highest weight loss was recorded in control treatment while lowest in grains treated with $0.4 \mathrm{~g} N$. tabacum.

All the treatment levels, singly and combined powder of $N$. tabacum and dust of pirimiphos-methyl caused varying degree of mortality in maize weevil, reduced number of emerged adults as well as the weight loss of the grains. Results suggest that the weevils would prefer to avoid maize grains treated with powder and dust. The ability of the plant powder to cause mortality of $S$. zeamais adults on maize grains can be attributed to contact toxicity of the powder on the weevil. Lajide et al (1998) had reported the effectiveness of some plant powders in controlling $S$. zeamais by causing adult mortality of the insect. The treatment with $0.4 \mathrm{~g} \mathrm{~N}$. tabacum powder had the highest weevil mortality as well as reduced number of adult emergence than any other treatments. The least weight loss was also recorded $0.4 \mathrm{~g}$ of N.tabacum. Similar effects of plant materials as crop seeds protectants have been observed in the treatment of cowpea and maize weevils (Asawalam et al., 2007; Ofuya and Dawodu, 2002; Adedire and Ajayi, 1996). Insecticidal property of any plant material would depend on the active constituents of the plant material. The active constituent in these plant materials appears to be responsible for their insecticidal properties against the maize weevil. Nicotiana tabacum has been reported to possess contact, stomach and respiratory poisoning properties attributed to the active constituent nicotine ( Lale, 2002; Stoll, 1988).

\section{Conclusion and recommendation}

Results obtained from this study revealed the potentials of $N$. tabacum powder as plant derived insecticides against maize weevil in Nigeria. The availability of tobacco locally and its potential as biopesticides make them candidates in upgrading traditional post-harvest protection practices. The effectiveness of N. tabacum in reducing damage and controlling S. Zeamais infestation in maize grains during storage could be encouraged and a possible means of ensuring a steady supply of good quality maize grains.

Although the Chemical composition of $N$. tabacum has been reported by several authors, its potential as a mix with other chemicals was investigated in this study. It was however found that $N$. tabacum singly was more effective on the maize weevils than when combined with a reduced rate of pirimiphos-methyl. This finding may suggest an antagonistic effect of the two treatments combined.

\section{Acknowledgments}

The authors are grateful to Mr. O.O. Omowaye for data collection and the Technologists in the laboratory of the Department of Crop, Soil and Pest Management, Federal University of Technology Akure for their assistance.

\section{References}

Adams, J. D. (1976). Weight loss caused by development of Sitophilus zeamais Motsch. in maize. J. stored Prod. Res., 12: 269-272.

Adedire and Ajayi. (1996). Assessment of the insecticidal properties of some plant extracts as grain protectants against the maize weevil S. zeamais Motschulsky. Nigeria Journal of Entomology, 13: 93-101.

Adedire, C. O and Lajide, L. (2003). Ability of extracts of ten tropical plant species to protect maize against infestation by the maize weevil, Sitophilus zeamais during storage. Nigeria Journal of Experimental Biology, 4 (2): 175-179.

Adedire, C.O and Lajide, L. (2001). Efficacy of powders of some tropical plants in the control of pulse beetle. Applied Tropical Agriculture, 6:11-15

Allotey, J. and Azalekor, W. (2000). Some aspects of the biology and control using botanicals of the rice moth, Corcyra cephalonica (Stainton), on some pulses. J. stored prod. Res., 36 (3): 235-243.

Appert, J. (1987). The Storage of Food grains and Seeds. The Tropical Agriculturist CTA, Macmillian publishers Ltd. London. 146 pp.

Asawalam, E. F, Emosairue, S.O., Ekeleme, F. and Wokocha, R C. (2007). Insecticidal effects of powdered parts of eight Nigerian plant species against maize weevil Sitophilus zeamais Motschulsky (Coleoptera: Curculionidae). ElectronicJournal of Environmental, Agriculture and Food Chemistry, 6 (11) 2526-2533. 
Baba, T. N. (1994). The ability of powders and slurries from ten plant species to protect stored grain from attacked by Prostephanus truncatus Horn (Coleoptera: Bostrichidae) and Sitophilus oryzae L. (Coleoptera: Curculionidae). J. stored prod. Res., 30: 297-301.

CIMMYT. (2004). Meeting World maize needs: Technological opportunities and priority for the public sector. [Online] Available: http://www.cimmyt.org/research/economics/map /facts_trends/maizeeft900/pdf. (Retrived June16, 2004).

Crespy, A. and Legarde R. (1973). Contributions to the study of maize smut, Ustilago maydis (D.C) Corda. Phystiatr phytopharm. 23: 33-36.

Dankyi, A. A., Anchirinah, V. M. and Apau, A. O. (1995). Profitability and impact of extension test plots on maize production (as cited in Mintah, P.) p 1-3.

ISTA. (1995). Handbook on vigour test methods for maize.117pp.

Kim, S. K. (1987). Achievements, challenges and future direction of hybrid maize research production in West Central Africa. In: Badu-Apraku, B., Akoroda, M. O., Ouedrago, M and Quin, F. M. (eds.) contributing to food self-sufficiency: Maize research and development in West Central Africa, pp 42-82.

Kling, J.A and Edmeades, G. (1997). Morphology and growth of maize - IITA/CIMMYT Research, Guide 9, IITA, Ibadan, Nigeria.

Lajide, L., Adedire C. O., Muse W. A. and Agele S. O. (1998). Insecticidal activity of powders of some Nigerian plants against the maize weevil (Sitophilus zeamais "Motsch") Entomological Society Nigeria Occasional Publications, 31: 227 - 235.

Lale, N.E.S. (2002). Stored Product Entomology and Acarology in tropical Africa. Mole publication, Maiduguri, Nigeria. 204pp.

Lawes Agricultural Trust. (1995). Genstat Software Version 5 Release 3.2 for Windows NT (Software for Statistical Analysis), Rothamstead Agricultural Station.

Ofuya, T. I. and Dawodu E. O. (2002). Aspects of Insecticidal Action of Piper guineense Schum and Thonn Fruit Powders against Callosobruchus maculatus (F.) (Coleoptera: Bruchidae). Nigerian Journal of Entomology, 19: $40-50$.

Purseglove, J. W. (1992). Tropical Crops: Monocotyledons. Longman Group, Singapore. 607pp.

Stoll G. (1988). Natural crop protection in the tropics and subtropics AGRECOL, Switzerland. 188 pp.

Zaidi and Singh. (2005). Morphology and growth of maize - IITA/CIMMYT Research, Guide 12, IITA, Ibadan, Nigeria. Pp 15-18.

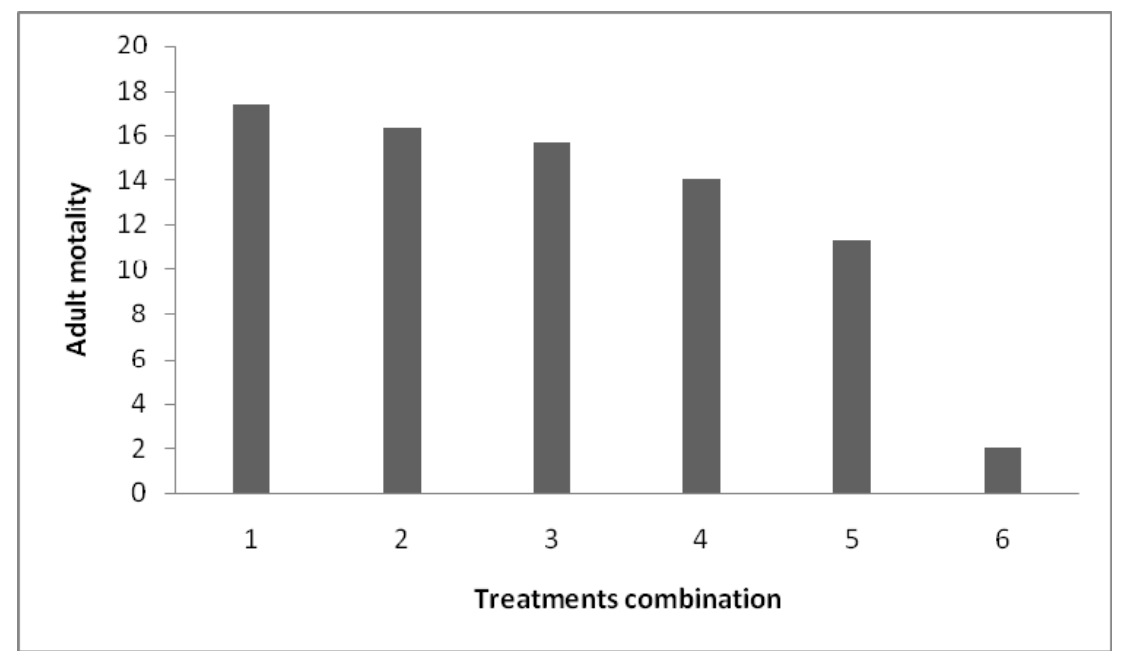

Figure 1. Effect of powder and dust on mortality of S. zeamais 


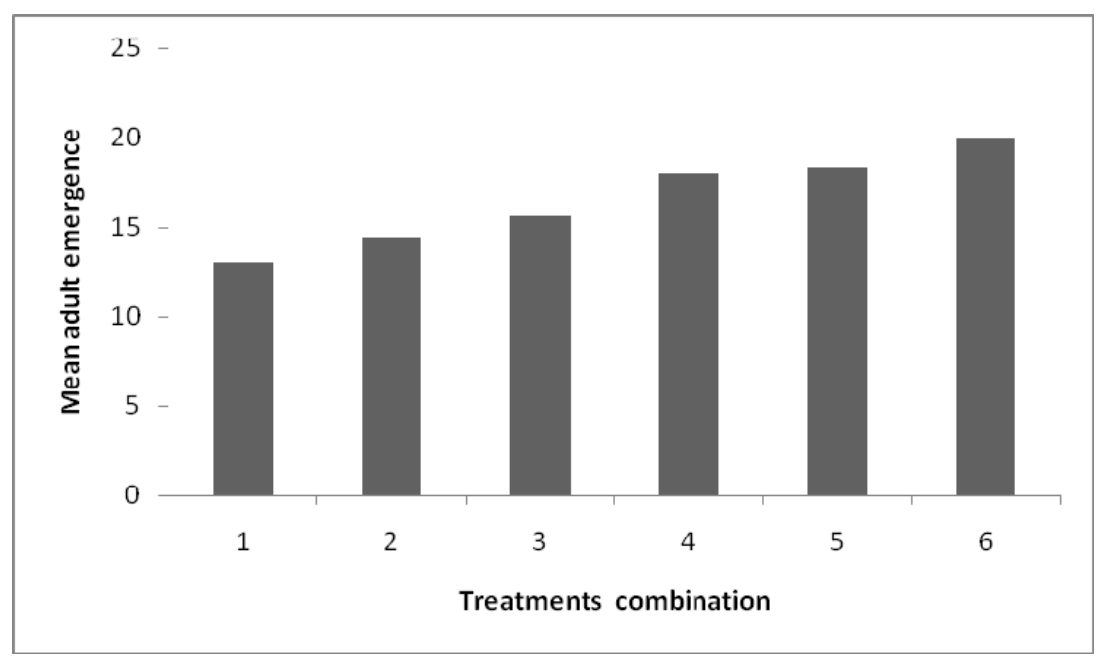

Figure 2. Effect of treatments on adult emergence of S. zeamais

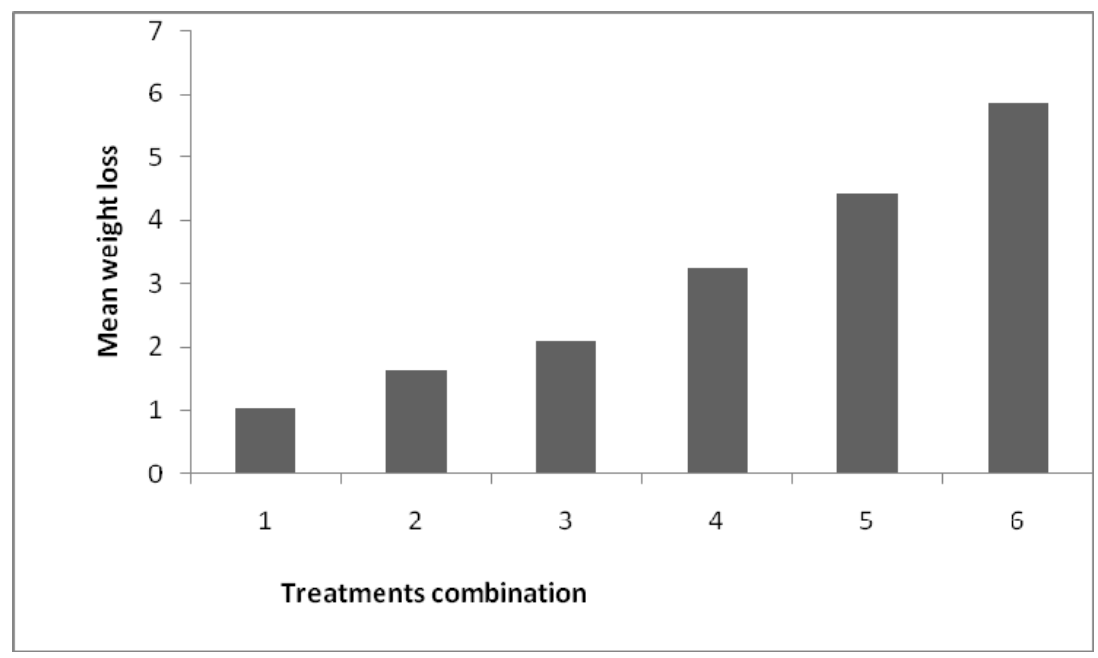

Figure 3. Mean weight loss of maize grain after emergence of S. zeamais 